Published in Springer Microbial Ecology, 2013

doi 10.1007/s00248-013-0210-7

\title{
Recovery of soil ammonia oxidation after long term zinc exposure is not related to the richness of the bacterial nitrifying community
}

Stefan Ruyters $^{*(1)}$, Dirk Springael ${ }^{(2)}$ and Erik Smolders ${ }^{(2)}$

Address: ${ }^{(1)}$ Department of Microbial and Molecular Systems, Lessius University College KU Leuven, Fortsesteenweg 30A, 2860 Sint-Katelijne-Waver, Belgium

${ }^{(2)}$ Department of Earth and Environmental Sciences, Division of Soil and Water Management, KU Leuven, Kasteelpark Arenberg 20, 3001 Heverlee, Belgium

*Corresponding author

email address: Stefan.ruyters@ lessius.eu

Tel: +32 (0)15/30 5593 Fax: +32 (0)15/305599 


\section{Abstract}

A soil sterilization-reinoculation approach was used to manipulate soil microbial diversity and to assess the effect of the diversity of the Ammonia Oxidizing Bacteria (AOB) on the recovery of the nitrifying community to metal stress (zinc). Gamma irradiated soil was inoculated with 13 different combinations of up to 22 different soils collected worldwide to create varying degrees of AOB diversity. Two months after inoculation, AOB amoA DGGE based diversity (weighted richness) varied more than 10 fold among the 13 treatments, the largest value observed where the number of inocula had been largest. Subsequently, the 13 treatments were either or not amended with $\mathrm{ZnCl}_{2}$. Initially, $\mathrm{Zn}$ amendment completely inhibited nitrification. After six months $\mathrm{Zn}$ exposure, recovery of the potential nitrification activity in the $\mathrm{Zn}$ amended soils ranged from $<10 \%$ to $>100 \%$ of the potential nitrification activity in the corresponding non-amended soils. This recovery was neither related to DGGE based indices of AOB diversity nor to the AOB abundance assessed two months after inoculation ( $>>0.05)$. However, recovery was significantly related $(\mathrm{r}=0.75)$ to the potential nitrification rate before $\mathrm{Zn}$ amendment and only weakly to the number of soil inocula used in the treatments $(\mathrm{r}=0.46)$. The lack of clear effects of AOB diversity on recovery may be related to an inherently sufficient diversity and functional redundancy of AOB communities in soil. Our data indicate that potential microbial activity can be a significant factor in recovery.

Key words: Recovery/Microbial diversity/DGGE/Nitrifying community/zinc 


\section{Introduction}

Microbial biodiversity only weakly affects generic soil microbial functions such as respiration and N-mineralisation, likely because of functional redundancy [12]. Biodiversity may however have a more important role in the functional stability (resistance and resilience) of the community following disturbances or stresses. Indeed, it has been proposed that the resistance of the soil microbial community, i.e. the ability to withstand a disturbance or stress, can increase with increasing biodiversity because of a higher likelihood that populations tolerant to the disturbance or stress are present [15]. Moreover, the resilience of a microbial community, i.e., its functional recovery rate after a disturbance or stress, may increase with increasing biodiversity, since more populations are available to adapt to the changing environment. However, there is little evidence that supports these hypotheses in soil microbial ecosystems. Girvan et al. [6] showed no difference in the recovery of carbon mineralization after copper $(\mathrm{Cu})$ amendment as a stress factor between two soils with intrinsic differences in microbial diversity. Griffiths et al. [7] reported that the addition of $\mathrm{Cu}$ initially reduced the decomposition rate of plant residues to a larger extent in soils that have been fumigated to decrease the microbial biodiversity compared to the non-fumigated soil. In contrast, adaptation after two months $\mathrm{Cu}$ exposure was as fast in the fumigated soil as in the non-fumigated soils [9]. Similar trends were observed in a study on the effect of a transient heat stress on nitrification [37].

To experimentally achieve different soil microbial biodiversities, these authors either applied fumigation [7] or dilution of soil samples and reinoculation in sterile soil [8; 37]. Both methods have their limitations. While dilution of the soil results into a gradual elimination of low abundant populations, the relative proportions of the dominant populations, presumed to 
contribute the most to the community function, will remain constant. Fumigation decreases the diversity by selectively eliminating fumigation-sensitive populations. An alternative method to manipulate soil microbial diversity, designated as sterilization-reinoculation methods, applies inoculation of a sterile soil with different bacterial species [21] or with soil aliquots containing different communities [10]. Rapid recolonization of sterile soil (within a few days) using the latter method has been shown [16]. This method has been used previously to ensure constant abiotic soil properties in experiments that investigated the toxicity of heavy metals to microbial processes $[2 ; 4 ; 30]$ as metal toxicity depends on soil properties such as $\mathrm{pH}$ or effective cation exchange capacity (eCEC). For instance, metal toxicity decreases with increasing eCEC due to decreasing metal bioavailability [34]. Hence, abiotic factors might obscure biological parameters and should be excluded in order to assess the effect of metal stress on the microbial community.

Several studies have demonstrated that the initial negative effect of increased $\mathrm{Zn}$ concentrations on nitrification disappears on the long term (> one year) due to selection of $\mathrm{Zn}$ tolerant species as indicated by a changing nitrifying community structure with increasing $\mathrm{Zn}$ concentrations [30; $20 ; 31 ; 38]$. It was speculated that this is the result of the proliferation of tolerant species already present in the community at the expense of $\mathrm{Zn}$ sensitive species which become less dominant or disappear [1]. Soil contains both ammonia oxidising bacteria (AOB) and archaea (AOA) [14]. Although the role of AOA in ammonia oxidation in soil is still debated [26], recovery of nitrification to $\mathrm{Zn}$ stress seems to be mainly due to the activity of AOB, rather than AOA [19; 31]. However, until now no information exists about the role of the AOB diversity in this recovery. The objective of this study is to relate the functional recovery of the potential nitrification after $\mathrm{Zn}$ stress to the AOB diversity. AOB diversity was experimentally varied using the sterilization-inoculation method. Sterilized soil was inoculated with different soils containing 
different AOB communities or soil mixtures thereof. After two months incubation, Zn was amended and recovery of the soil bacterial nitrifying community was determined after six months $\mathrm{Zn}$ exposure by comparing the potential nitrification rate (PNR) in $\mathrm{Zn}$ amended soils to this of the control soil which did not receive $\mathrm{Zn}$. The AOB diversity was quantified using indices calculated from AOB amoA DGGE profiling and by the number of soils used as inoculum which is a technique-independent index of diversity.

\section{Materials and methods}

\section{Soil treatments}

Ter Munck (TM) soil (Belgium) [33] was used as the matrix soil for creating 14 soil treatments with different microbial diversity, including one non-inoculated control. This was achieved by inoculation of sterile TM soil with aliquots from other soils (see below). Sterile TM soil was obtained by $\gamma$-irradiation (Co-60) at $25 \mathrm{kGy}$ [36]. Sterility of the soil was confirmed by the absence of CFU on LB agar medium plated with a soil extract (1:5 Soil:Liquid ratio) after 10 days of incubation at $30{ }^{\circ} \mathrm{C}$. Soil $\mathrm{pH}\left(\mathrm{CaCl}_{2} 0.01 \mathrm{M}\right)$ remained unchanged after irradiation $(\mathrm{pH}$ 6.2). The irradiated soil had $11 \%$ clay, $70 \%$ silt, $1 \%$ organic $\mathrm{C}$ and the effective Cation Exchange Capacity (eCEC) was $12.2 \mathrm{cmol}_{\mathrm{c}} \mathrm{kg}^{-1}$ [33]. The soil was stored in a closed container at room temperature for two weeks and then divided into 14 portions of $500 \mathrm{~g}$. At inoculation and during the course of the experiment, the soil was not handled in sterile conditions and only covered with parafilm to ensure aerobic conditions.

Twenty two top soils used for inoculation were collected worldwide (six soils from Belgium, three from Australia, three from Spain, one from Italy, Greece, Denmark, Sweden, Hungary, Canada, Vietnam, USA, Kenya and Nigeria) and were stored air-dry. After rewetting to $70 \%$ of 
field capacity, these soils showed different AOB amoA DGGE profiles and detectable potential nitrification activity. The $\mathrm{pH}$ of the soils ranged from 4.0 to 7.7. The individual soils or mixtures thereof were inoculated into sterile TM soil at $5 \mathrm{wt} \%$ in total (25 g soil in $475 \mathrm{~g}$ sterile TM soil). The soils for inoculation were selected based on contrasting AOB diversities as suggested by their AOB amoA DGGE profiles. Moreover, dedicated mixtures of the individual soils were included assuming that diversity increases with an increasing number of inoculum soils. Eight treatments were inoculated with one of eight different soils as listed in Table 1 (single soil inocula treatments) and four treatments were inoculated with mixtures of these soils (mixture 1-4; Table 1). Mixture 5 contained the same eight and 14 other soils (four soils from Belgium, three from Australia, two from Spain, one from Italy, Canada, Vietnam, USA and Nigeria ) (Table 1). In case of inoculation with mixtures, the $25 \mathrm{~g}$ inoculum consisted of equal fractions (dry weight based) of each soil except for the Teso and Souli soils that had a lower AOB amoA abundance than the other soils $\left(6.4 \times 10^{5}\right.$ and $6.4 \times 10^{6}$, respectively). Therefore, Teso and Souli soils were added at 5-fold larger doses than the other soils in the mixtures. A $14^{\text {th }}$ treatment was not

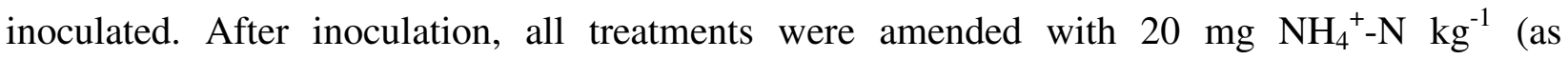
$\left.\left(\mathrm{NH}_{4}\right)_{2} \mathrm{SO}_{4}\right)$ to stimulate nitrification and the establishment of a nitrifying microbial community. Treatments were moistened to $20 \%$ moisture content, well homogenized and incubated in $1 \mathrm{~L}$ plastic pots (height $14 \mathrm{~cm}$, diameter $11 \mathrm{~cm}$ ) as one replicate for two months at $25{ }^{\circ} \mathrm{C}$ while covered with parafilm, before $\mathrm{Zn}$ amendment. 
Table 1: Soils and soil mixtures used to inoculate the sterile Ter Munck soil to vary the microbial diversity. Eight treatments were inoculated with one of the eight soils listed. Four other treatments (Mixture 1-4) were inoculated with a mixtures of these eight soils as indicated. Mixture 5 consisted of all these soils and 14 other soils (not shown).

\begin{tabular}{llcccc}
\hline Soil name & Country & Mixture 1 & Mixture 2 & Mixture 3 & Mixture 4 \\
\hline Teso & Kenya & & $\mathrm{X}$ & $\mathrm{X}$ & $\mathrm{X}$ \\
Guadalajara & Spain & $\mathrm{X}$ & & & \\
Zeveren & Belgium & & $\mathrm{X}$ & $\mathrm{X}$ & \\
Souli $^{1}$ & Greece & & & $\mathrm{X}$ & $\mathrm{X}$ \\
Borris & Denmark & & $\mathrm{X}$ & $\mathrm{X}$ \\
Nagyhörcsök & Hungary & $\mathrm{X}$ & & $\mathrm{X}$ & \\
Kasterlee & Belgium & $\mathrm{X}$ & & $\mathrm{X}$ & \\
Kövlinge & Sweden & & $\mathrm{X}$ & $\mathrm{X}$ & \\
\hline
\end{tabular}

The weight proportion of these soils in the mixtures was 5 times higher than that of the other soils to equalize the proportion of the AOB abundance of each soil in the mixture

\section{Recovery experiment}

The recovery experiment started two months after inoculation. Prior to $\mathrm{Zn}$ amendment, soil DNA was extracted in duplicate samples from all treatments to assess the initial AOB diversity and AOB abundance (as described below). In addition, the initial Potential Nitrification Rate (PNR) was determined in duplicate samples per treatment (two technical replicates) and the initial $\mathrm{Zn}$ tolerance was determined on one soil sample per treatment. Subsequently, each soil treatment was divided into four portions (125 g) of which two were amended with $1500 \mathrm{mg} \mathrm{Zn} \mathrm{kg}^{-1}$ (as $\mathrm{ZnCl}_{2}$ ) and two control portions received no $\mathrm{Zn}$. This resulted in 56 soils (14 treatments each divided into two non- $\mathrm{Zn}$ amended soils and two $\mathrm{Zn}$ amended soils). The soils were incubated for an extra 6 months in perforated $200 \mathrm{ml}$ plastic pots (height $10 \mathrm{~cm}$, diameter $5 \mathrm{~cm}$ ) covered with 
parafilm in darkness at $25^{\circ} \mathrm{C}$. After one week incubation, soils were leached with artificial rain water to remove excess of salts due to $\mathrm{Zn}$ application as described by Oorts et al. [25]. Non-Zn amended soils were also leached. The soil $\mathrm{pH}$ was subsequently measured. Soil pH decreases due to $\mathrm{Zn}^{2+}$ salt amendment and nitrification and, conversely, $\mathrm{pH}$ affects $\mathrm{Zn}$ bioavailability and nitrification activity. The $\mathrm{pH}$ of the $\mathrm{Zn}$ amended soils decreased by $1 \mathrm{pH}$ unit three weeks after $\mathrm{Zn}$ application and the soils were limed with $0.41 \mathrm{~g} \mathrm{CaO} \mathrm{kg}^{-1}$ to restore soil $\mathrm{pH}$ to 6.2 as in non$\mathrm{Zn}$ amended soils. The soil $\mathrm{pH}$ was not determined during the remaining incubation period. Simultaneously with liming, $150 \mathrm{mg} \mathrm{NH}_{4}{ }^{+}-\mathrm{N} \mathrm{kg}^{-1}$ was applied to $\mathrm{Zn}$ amended and control soil samples to accelerate recovery of the potential nitrification [31]. Soils were leached once more at two months after $\mathrm{Zn}$ amendment with artificial rain water and $\mathrm{CaCl}_{2}(0.01 \mathrm{M})$ to remove produced $\mathrm{NO}_{3}{ }^{-} \mathrm{N}$ which can inhibit nitrification, followed by application of $150 \mathrm{mg} \mathrm{NH}{ }^{+}-\mathrm{N} \mathrm{kg}^{-1}$. A third leaching was conducted two weeks before determining recovery, without a subsequent $\mathrm{NH}_{4}{ }^{+} \mathrm{N}$ application. After six months $\mathrm{Zn}$ exposure (eight months incubation in total), samples were taken from all soils to measure the PNR and calculate the recovery.

\section{Potential nitrification rate $(P N R)$}

Soil nitrification was quantified as the Potential Nitrification Rate (PNR) [33] and performed in suspension at a $\mathrm{pH}$ of 6.2 . Briefly, soil moisture content of the soil samples was adjusted to $20 \%$ 7 days prior to the start of the assay. Then, soil samples were suspended in $0.01 \mathrm{M} \mathrm{CaCl}_{2}$ with 25 $\mathrm{mM}$ 2-(N-morpholino)ethanesulfonic acid (MES) $\left(\mathrm{pH}\right.$ 6.2) $\left(2 \mathrm{~g}\right.$ soil in $10 \mathrm{ml}$ liquid) and $\mathrm{NH}_{4} \mathrm{Cl}$ solution $\left(15 \mathrm{mg} \mathrm{ml}^{-1}\right)$ was added at an added concentration of $200 \mathrm{mg} \mathrm{NH}_{4}^{+}-\mathrm{N} \mathrm{kg}^{-1}$ dry soil. Samples of $3 \mathrm{ml}$ were taken immediately after $\mathrm{NH}_{4}{ }^{+}-\mathrm{N}$ addition and after seven days head-overend $(28 \mathrm{rpm})$ incubation at $20^{\circ} \mathrm{C}$. Potassium chloride $4 \mathrm{~N}$ was added to a final concentration of 1 
$\mathrm{N}$, samples were shaken head-over-end for two hours (28 rpm), centrifuged (3000 g, $10 \mathrm{~min})$ and the $\mathrm{NO}_{3}{ }^{-} \mathrm{N}$ concentration was measured colorimetrically in the supernatant (SA 40, Skalar, The Netherlands). The PNR was calculated as the amount of nitrate produced per kg dry soil over time (mg NO${ }_{3}^{-}-\mathrm{N} \mathrm{kg}^{-1} \mathrm{~d}^{-1}$ ). The PNR at two months was determined on two soil samples for each inoculated treatment, the PNR at 8 months was determined on one replicate of each of the four pots.

\section{Zn tolerance assay}

Zinc tolerance was measured by means of the spike-on-spike test as described by Mertens et al. [20]. Briefly, $\mathrm{ZnCl}_{2}\left(50 \mathrm{mg} \mathrm{ml}^{-1}\right)$ was added to a $2.5 \mathrm{~g}$ soil sample suspended in $\mathrm{CaCl}_{2} 0.01 \mathrm{M}$ (1:10 solid:liquid ratio) with $25 \mathrm{mM}$ MES buffer ( $\mathrm{pH}$ 6.2) at added concentrations of 0 (two samples), 15, 30, 75, 150, 300 and $500 \mathrm{mg} \mathrm{Zn}^{-1}$. Ammonium chloride solution $\left(15 \mathrm{mg} \mathrm{ml}^{-1}\right)$ was added at a concentration of $100 \mathrm{mg} \mathrm{NH}_{4}{ }^{+}-\mathrm{N} \mathrm{kg}^{-1}$. The $\mathrm{pH}$ in suspension was adjusted immediately after $\mathrm{N}$ addition and every other day during the seven day incubation period to $\mathrm{pH}$ $6.2 \pm 0.1$ by adding $0.1 \mathrm{M} \mathrm{NaOH}$ or $\mathrm{HCl}$ if required. The samples were incubated at $20{ }^{\circ} \mathrm{C}$ and continuously shaken head-over-end (28 rpm). Nitrate concentrations were measured as described in the PNR assay at the start of the experiment and after seven days, and the potential nitrification rate was calculated as the amount of nitrate produced per $\mathrm{kg}$ dry soil over time $\left(\mathrm{mg} \mathrm{NO}_{3}{ }^{-}-\mathrm{N} \mathrm{kg}^{-1}\right.$ $\mathrm{d}^{-1}$ ). Soluble $\mathrm{Zn}$ in the extract was measured in the supernatant after centrifugation of the soil suspension (3000 g, 15 min) using ICP-OES (Perkin Elmer Optima 3300 DV, Norwalk, CT, USA). The potential nitrification rate in suspension was related to measured equilibrium $\mathrm{Zn}$ concentrations in the $\mathrm{CaCl}_{2}$ soil extract. Zinc tolerance was expressed as the dissolved $\mathrm{Zn}$ concentration at which the potential nitrification rate was $50 \%$ reduced compared to a control 
suspension (no Zn added) (EC50) which was interpolated from the dose-response curve fitted by log-logistic modeling using the Marquardt method (proc NLIN, SAS 9.2, NC, USA) [3]. Zinc tolerance was determined on one soil sample of each inoculated treatment after two months incubation.

amoA $A O B$ abundance and diversity

Soil DNA was extracted (0.5 g) and purified using the MO BIO Powersoil DNA Isolation Kit according to the manufacturer's protocol (MO BIO laboratories, California, USA). Phylogeny of the AOB amoA gene, responsible for the first step in nitrification, has previously been shown to be congruent with $16 \mathrm{~S}$ rRNA phylogeny [27] suggesting that the amoA gene is a suitable marker to determine the AOB community structure and diversity [13]. Copy numbers of AOB amoA were quantified in duplicate in each DNA extract by means of real-time PCR using a Corbett Rotor-Gene 3000 real-time PCR cycler (Qiagen, Venlo, The Netherlands) as described previously [31] using primers $a m o A-1 \mathrm{~F}$ and $a m o \mathrm{~A}-2 \mathrm{R}$ [29]. Dilution series of purified PCR products from the cloned amoA gene of Nitrosomonas europaea ATCC 19718 (AOB) were used as qPCR standards. The efficiency of the reaction was 0.84. Copy numbers of AOB amoA were transformed to the numbers of $\mathrm{AOB}$ assuming that on average 2.5 amoA copies were present per AOB cell [23]. PCR amplification of AOB amoA using primers GC-amoA-1F* and amoA-2R [29; 35] was performed at an annealing temperature of $60{ }^{\circ} \mathrm{C}$ as described [19]. Denaturing Gradient Gel Electrophoresis (DGGE; Ingeny, Goes, The Netherlands) profiling of AOB amoA was performed on $6 \%$ polyacrylamide gels with a linear gradient of $40-60 \%$, run for $16 \mathrm{~h}$ at $60{ }^{\circ} \mathrm{C}$ and $100 \mathrm{~V}$ as described [20]. 


\section{Data analysis}

The initial PNR, AOB diversity and AOB abundance, i.e. values after two months incubation prior to $\mathrm{Zn}$ amendment, is reported as average values of two replicates per treatment. Duncan grouping $(\mathrm{p}<0.05)$ was performed to detect significant differences among treatments. Differences in initial $\mathrm{Zn}$ tolerance among treatments were determined by analyzing the $95 \%$ confidence limits of the EC50 value and treatments were manually grouped in statistical different groups if confidence intervals were not overlapping. Each treatment was separated in two $\mathrm{Zn}$ amended and non-Zn amended soils and the PNR was measured on these duplicates six months after Zn amendment. Recovery was quantified as the ratio of the PNR in the $\mathrm{Zn}$ amended soils to the average of the corresponding PNR in the non-Zn amended soils after six months $\mathrm{Zn}$ exposure according to:

recovery $(\%)=\frac{\text { average } \mathrm{PNR}_{\mathrm{Zn} 6 \text { months }}}{\text { average } \mathrm{PNR}_{\text {controls } 6 \text { months }}} \times 100 \quad$ (Equation 1$)$

The standard deviation of recovery was calculated with the standard deviation of the nominator and denominator assuming no covariance. Significant recovery was assumed when the PNR in the non-Zn amended soils did not significantly differ from the PNR in the $\mathrm{Zn}$ amended soils (ttest, $\mathrm{p}>0.05)$. Stepwise multiple regression analysis was performed to analyze recovery in relation to $\mathrm{AOB}$ diversity, abundance, activity and $\mathrm{Zn}$ tolerance of the treatments after two months incubation and prior to Zn amendment (proc REG, SAS 9.2, NC, USA; significant limits to enter a variable set at $\mathrm{p}=0.15)$. Pearson correlation coefficients among variables were calculated (proc CORREL, SAS 9.2, NC, USA). For both analyses, average values per treatment were used for the initial AOB diversity, initial AOB abundance, initial PNR and initial Zn tolerance whereas the duplicate recovery values were used individually. The DGGE profiles were 
analyzed using Gelcompar 4.6 (Applied Maths, Belgium). To determine the AOB diversity all bands in each DGGE profile were manually assigned. The AOB diversity based on amoA DGGE profiling was expressed as the weighted richness as proposed by Mertens et al. [18]. The weighted richness is a dimensionless value representing the number of bands corrected for the gradient span on the DGGE gel and is a measure for the number of different phylotypes present and the genetic variability within these phylotypes [17]. The number of bands in the DGGE profile, the Shannon-Wiener index based on amoA DGGE profiling were used as additional indices for diversity to show whether relations are due to the use of a particular diversity index. The number of soils used in the different inocula - i.e. a nominal proxy of diversity - is a technique-independent diversity index, since a larger AOB diversity is expected with increasing number of soils used in the inocula. However, it does not account for possible shifts in diversity upon subsequent growth of the communities after inoculation. Band matching classes grouping similar bands across the DGGE profiles were automatically defined in Gelcompar using default parameters and manually checked. Band matching data (band presence and intensity) obtained from the DGGE analysis were used to graphically compare the AOB community in the single soil inocula treatments with the $\mathrm{AOB}$ community in the treatments inoculated with the mixtures using two-dimensional nMDS ordination based on the Bray-Curtis similarity measure (default parameters, PC-ORD v5) [28]. 


\section{Results}

Establishment and diversity of the AOB community after two months incubation and prior to Zn amendement

No potential nitrification activity (PNR) was detected after two months incubation prior to $\mathrm{Zn}$ amendment in the non-inoculated treatment (the soil that was sterilized at the start) and only a few, weak bands were observed in the AOB amoA DGGE profile (Figure 1). The PNR after two months incubation in the inoculated treatments ranged from $1.5-4.5 \mathrm{mg} \mathrm{NO}_{3}^{-}-\mathrm{N} \mathrm{kg}^{-1} \mathrm{~d}^{-1}$ in treatments inoculated with soil mixtures 1 to 5 and from $0.5-3.5 \mathrm{mg} \mathrm{NO}_{3}{ }^{-}-\mathrm{N} \mathrm{kg}^{-1} \mathrm{~d}^{-1}$ in single soil inocula treatments (Table 2). The AOB abundance was of the same order of magnitude for all inoculated treatments $\left(6.6 \times 10^{7} \mathrm{AOB} \mathrm{g}^{-1}\right.$ soil on average; Table 2$)$ and comparable with values previously reported in soils $[14 ; 19 ; 22 ; 24 ; 31]$. Zinc tolerance before $\mathrm{Zn}$ exposure was low for

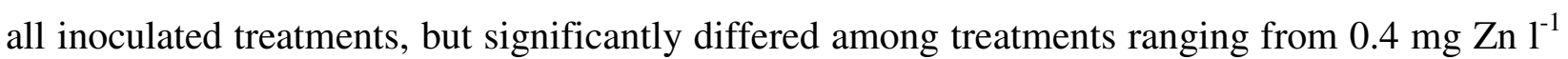
in the treatment inoculated with Teso (most sensitive) to $7 \mathrm{mg} \mathrm{Zn}^{-1}$ in the treatment inoculated with the Zeveren or Nagyhörcsök soil (Table 2). Expected AOB weighted richness, calculated based on the AOB amoA DGGE profiles of the soils that served as inocula (DGGE profiles not shown) were compared to the measured AOB weighted richness based on the AOB amoA DGGE profiling of the inoculated treatments two months after inoculation and prior to $\mathrm{Zn}$ amendment (Table 2). 
Table 2: Relevant microbial properties of re-inoculated soils two months after inoculation (before Zn exposure) (diversity, abundance, PNR and zinc tolerance) and recovery after 6 months $\mathrm{Zn}$ exposure. The AOB diversity is the weighted richness based on the DGGE bands. The Shannon Wiener index, number of bands and the number of soil inocula are shown in the Supplementary information (Table S-1). The potential nitrification rate (PNR) refers to the non-Zn amended soils. Recovery is calculated as given in equation 1. Significantly different means $(\mathbf{p}<0.05)$ are denoted with different letters and standard deviations are given in brackets $(n=2)$.

\begin{tabular}{|c|c|c|c|c|c|c|c|c|c|c|c|c|}
\hline \multirow{2}{*}{$\begin{array}{l}\text { Treatment } \\
\text { (inocula) }\end{array}$} & \multirow{2}{*}{$\begin{array}{c}\text { Expected }^{\mathbf{1}} \\
\text { AOB } \\
\text { Diversity } \\
\text { (Richness) } \\
83\end{array}$} & \multicolumn{2}{|c|}{$\begin{array}{c}\text { Measured } \\
\text { AOB Diversity } \\
\text { (Richness) }\end{array}$} & \multicolumn{2}{|c|}{$\begin{array}{c}\text { AOB } \\
\text { abundance }^{2} \\
(\log \text { AOB g } \\
\text { soil })\end{array}$} & \multirow{2}{*}{ 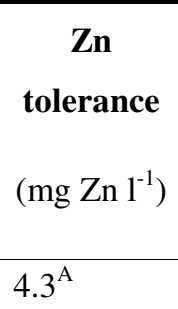 } & \multicolumn{2}{|c|}{$\begin{array}{c}\text { PNR } \\
(2 \text { months })^{2}\end{array}$} & \multicolumn{2}{|c|}{$\begin{array}{c}\text { PNR } \\
{\text { (8 months })^{2}}^{2}\end{array}$} & \multicolumn{2}{|c|}{ Recovery $^{2}$} \\
\hline & & $33^{\mathrm{CDE}}$ & (4.5) & $8.0^{\mathrm{ABC}}$ & $(0.4)$ & & $2.8^{\mathrm{C}}$ & $(0.04)$ & $4.6^{\mathrm{F}}$ & (1.3) & 77 & (80) \\
\hline Mixture 2 & 72 & $94^{\mathrm{AB}}$ & (16.5) & $7.7^{\mathrm{AB}}$ & $(0.3)$ & $1.0^{\mathrm{D}}$ & $1.6^{\mathrm{E}}$ & (0.004) & $6.9^{\mathrm{BCD}}$ & (1.2) & 8 & (9) \\
\hline Mixture 3 & 196 & $71^{\mathrm{BC}}$ & nd & $7.7^{\mathrm{ABC}}$ & $(0.2)$ & $2.0^{\mathrm{CD}}$ & $2.6^{\mathrm{CD}}$ & $(0.5)$ & $2.2^{\mathrm{EF}}$ & $(0.7)$ & 21 & (27) \\
\hline Mixture 4 & 97 & $98^{\mathrm{AB}}$ & (3.5) & $7.4^{\mathrm{BCD}}$ & $(0.1)$ & $1.2^{\mathrm{D}}$ & $1.6^{\mathrm{E}}$ & $(0.1)$ & $6.4^{\mathrm{BCD}}$ & $(0.4)$ & 3 & (3) \\
\hline Mixture 5 & $>>$ & $114^{\mathrm{A}}$ & (51.3) & $7.8^{\mathrm{ABC}}$ & $(0.3)$ & $4.6^{\mathrm{A}}$ & $4.5^{\mathrm{A}}$ & $(0.2)$ & $1.9^{\mathrm{F}}$ & (0.9) & 138 & (122) \\
\hline Kövlinge & 5 & $6^{\mathrm{E}}$ & (0.6) & $6.4^{\mathrm{E}}$ & $(0.7)$ & $2.3^{\mathrm{BC}}$ & $0.1^{\mathrm{F}}$ & (0.04) & $7.7^{\mathrm{CB}}$ & $(0.5)$ & 1 & (1) \\
\hline Nagyhörcsök & 17 & $7^{\mathrm{E}}$ & (0.6) & $8.3^{\mathrm{A}}$ & (0.6) & $6.5^{\mathrm{A}}$ & $2.3^{\mathrm{D}}$ & $(0.01)$ & $11.1^{\mathrm{A}}$ & $(0.04)$ & 89 & (21) \\
\hline Kasterlee & 46 & $10^{\mathrm{E}}$ & $(0.1)$ & $7.6^{\mathrm{BC}}$ & $(0.5)$ & $5.9^{\mathrm{A}}$ & $3.4^{\mathrm{B}}$ & $(0.3)$ & $2.6^{\mathrm{EF}}$ & (0.003) & 124 & (57) \\
\hline Borris & 46 & $20^{\mathrm{ED}}$ & $(0.1)$ & $7.4^{\mathrm{DC}}$ & $(0.7)$ & $3.9^{\mathrm{B}}$ & $1.4^{\mathrm{E}}$ & $(0.1)$ & $7.5^{\mathrm{BCD}}$ & (0.9) & 3 & (3) \\
\hline Souli & 15 & $57^{\mathrm{BCD}}$ & $(9.7)$ & $8.0^{\mathrm{AB}}$ & $(0.2)$ & $5.7^{\mathrm{A}}$ & $0.6^{\mathrm{F}}$ & $(0.1)$ & $4.8^{\mathrm{ED}}$ & (3.1) & 1 & (1) \\
\hline Zeveren & 31 & $67^{\mathrm{BC}}$ & (1.8) & $7.9^{\mathrm{ABC}}$ & $(0.1)$ & $6.6^{\mathrm{A}}$ & $1.3^{\mathrm{E}}$ & $(0.1)$ & $2.0^{\mathrm{F}}$ & (1.8) & 45 & (51) \\
\hline Guadalajara & 20 & $70^{\mathrm{BC}}$ & (8.2) & $7.9^{\mathrm{AB}}$ & $(0.4)$ & $3.3^{\mathrm{BC}}$ & $0.5^{\mathrm{F}}$ & $(0.1)$ & $8.5^{\mathrm{B}}$ & (1.1) & 6 & (4) \\
\hline Teso & 36 & $81^{\mathrm{AB}}$ & (19.3) & $7.0^{\mathrm{D}}$ & $(0.5)$ & $0.4^{\mathrm{CD}}$ & $1.3^{\mathrm{E}}$ & $(0.1)$ & $5.4^{\mathrm{CD}}$ & (1.0) & 5 & (3) \\
\hline
\end{tabular}

${ }^{1}$ The expected AOB diversity is derived from the amoA DGGE profiles of the soils before inoculation $\left(\right.$ see text); ${ }^{2}$ Standard deviation is given in brackets $(\mathrm{n}=2)$; $>>$ Richness of mixture 5 could not be estimated, but is assumed to be very high, since it is comprised of 22 soils; nd: not determinable 
The values of the additional diversity measures (number of bands and Shannon-Wiener index) are reported in Supplementary Information Table 1. As expected, the AOB weighted richness and number of bands was low in the treatments inoculated with the Kövlinge and Nagyhörcsök soils. In contrast, the measured weighted richness was well below the expected weighted richness in the treatments inoculated with the Borris and Kasterlee soils. For all the single soil inocula treatments, except for the treatment inoculated with the Kasterlee soil, the measured number of bands was higher than the expected number of bands (Supplementary Information Table 1). In the treatments inoculated with mixtures, the expected AOB weighted richness was calculated as the sum of the $A O B$ weighted richness measured in the soils used in the mixture before inoculation. For the treatments inoculated with mixtures the measured AOB weighted richness was similar (mixture 4), larger (mixture 2) or lower (mixture 1, 3 and 5) than what was expected, whereas the number of bands after inoculation was lower than expected for all treatments (Supplementary Information Table 1). The measured AOB weighted richness and number of bands of the treatments inoculated with mixture 2, 4 and 5 was larger than those of the treatments inoculated with single soils (Table 2). The AOB amoA DGGE profiles of the treatments inoculated with the soil mixtures showed resemblances with those of single soil inocula treatments of the soils that were used in these mixtures (Figure 1). Figure 1 in Supplementary Information shows the two-dimensional nMDS ordination graphs based on Bray-Curtis similarity for the treatments inoculated with the mixtures compared to the single soil inocula treatments inoculated with the soils used in the mixture. In total, both axes explained at least $60 \%$ of the variation among all mixtures. The established community in the treatments inoculated with the mixtures was structurally a mixture of the single soil inocula treatments except for the treatment inoculated with mixture 2 where the Teso soil dominated the AOB community. Teso soil was 
inoculated 5 times more than other soils to equalize the inoculated abundance of the AOB in the mixtures. Note that mixture 5 consisted of more than the eight soils displayed, the remaining 14 soils were not used as single inocula and, therefore, not included in the graph. In conclusion, communities with varying AOB diversity established among treatments and overall, the AOB diversity was increased by inoculating mixtures of several soils.

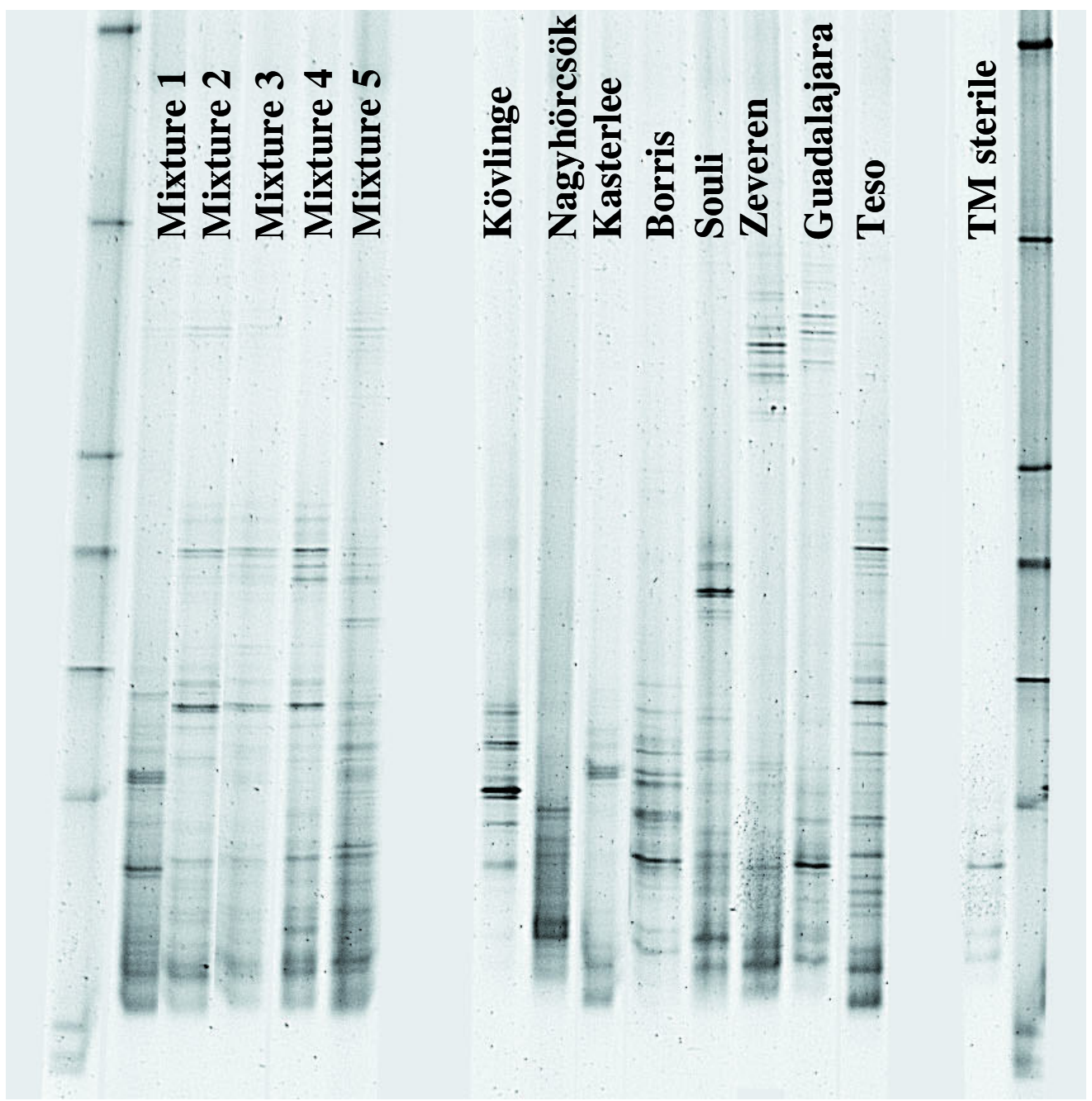

Figure 1: AOB amoA DGGE profiles of the inoculated treatments after two months incubation in the absence of Zn. 


\section{Recovery in inoculated treatments after six months Zn exposure}

One week after $\mathrm{Zn}$ contamination, potential nitrification activity was undetected in all $\mathrm{Zn}$ amended soils. The PNR in the non-Zn amended soils were similar to the PNR in the corresponding treatments after 2 months incubation before $\mathrm{Zn}$ addition. After eight months incubation, potential nitrification activity restored $\left(\mathrm{PNR}=11 \mathrm{mg} \mathrm{NO}_{3}^{-}-\mathrm{N} \mathrm{kg}^{-1} \mathrm{~d}^{-1}\right)$ in the non- $\mathrm{Zn}$ amended soils of the non-inoculated treatment and its AOB amoA DGGE showed two weak bands suggesting that some AOB phylotypes established, probably due to non-sterile handling (data not shown). No recovery of the PNR was recorded in the Zn amended soils of the noninoculated treatment. No significant recovery of the potential nitrification was observed in the $\mathrm{Zn}$ amended soils of seven of the inoculated treatments (recovery $<10 \%$; Table 2). In contrast, full recovery was observed in the $\mathrm{Zn}$ amended soils of the treatment inoculated with mixture 5 (138\% recovery), the Nagyhörcsök (89\%) and the Kasterlee (124\%) soil (Table 2). Partial recovery ranging from $21 \%-77 \%$ was observed in the $\mathrm{Zn}$ amended soils of the treatments inoculated with mixtures 1, 3 and with the Zeveren soil. Recovery was not significantly correlated with the initial AOB weighted richness (Table 3 and Figure 2). Other AOB diversity indices were correlated to the AOB weighted richness (Table 3). Recovery was significantly, and positively, correlated to the number of soil inocula, the initial Zn tolerance and, most strongly, to the initial PNR (Table 3 and Figure 2). Multiple regression showed that, among the variables displayed in Table 3, only the initial PNR and initial Zn tolerance were significantly correlated to recovery (partial $\mathrm{R}^{2}=$ $0.56, \mathrm{p}<0.15$ and partial $\mathrm{R}^{2}=0.10, \mathrm{p}<0.15$, respectively). Similarly, when grouping the treatments inoculated by either mixtures or single soils or with similar initial PNR values, no direct effect of the AOB diversity on recovery was observed (Table 4). 

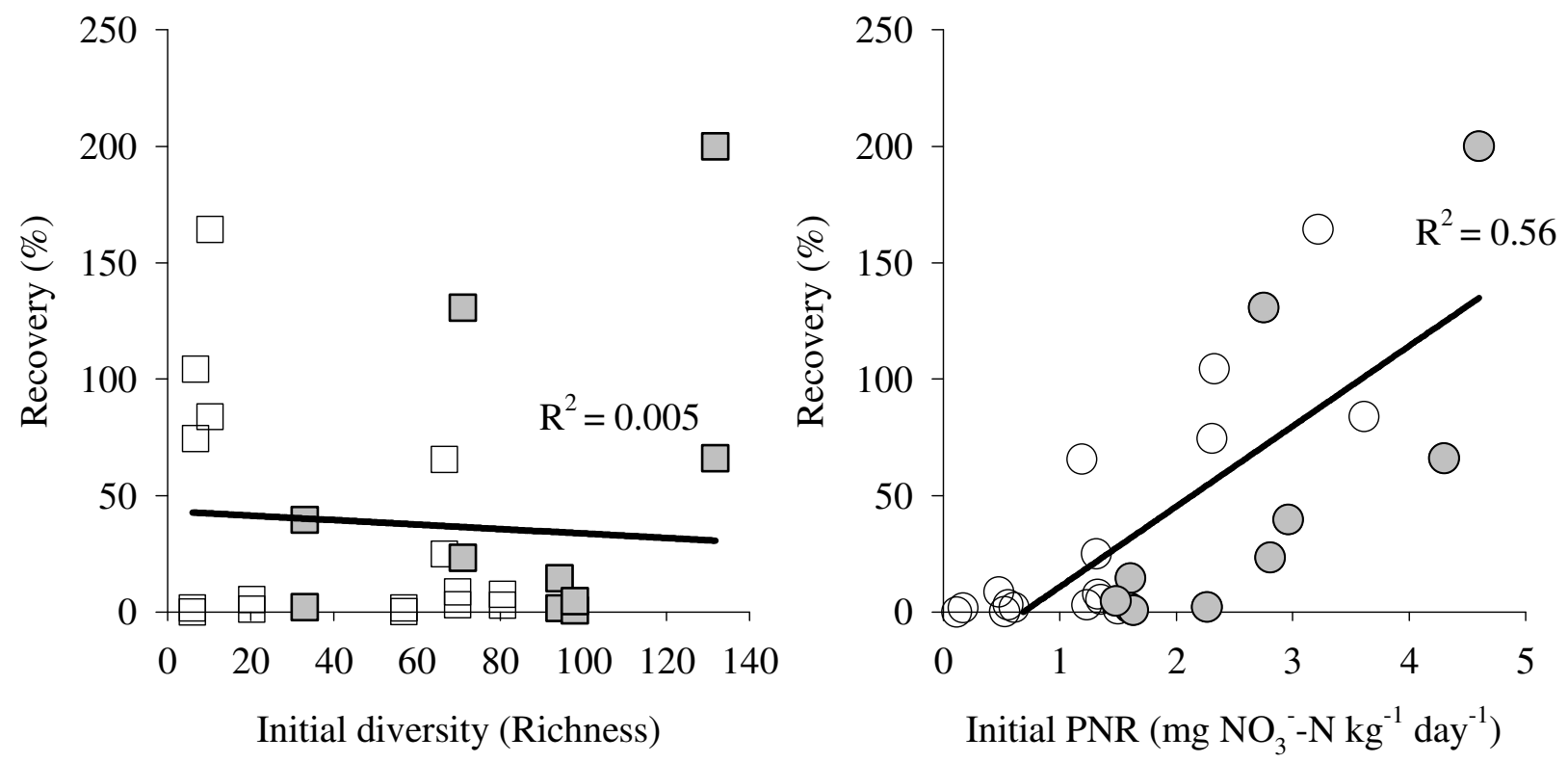

Figure 2: Recovery (equation 1) of the potential nitrification after long term $\mathrm{Zn}$ exposure in relation to the initial diversity of the corresponding inoculated treatments ( $\square$ weighted richness, left graph), and to the initial potential nitrification activity ( $\odot$ PNR, right graph). Initial diversity and initial PNR are average values of two technical replicates, two replicate values of recovery are given. Linear regression was used to evaluate the relation (weighted richness: $R^{2}=0.005, p=0.63 ;$ PNR: $R^{2}=0.56, p<0.001$ ). Gray shaded symbols: treatments inoculated with soil mixtures; open symbols: single soil inocula treatments. 
Table 3: Pearson correlation (r-values) among microbial properties before Zn stress (all properties except recovery) and recovery after Zn stress.

\begin{tabular}{|c|c|c|c|c|c|c|c|c|}
\hline & Initial & $\mathrm{Zn}$ & AOB & $\mathrm{AOB}$ & \# AOB & AOB Shannon & \# & \\
\hline & PNR & tolerance & abundance & richness & bands & Wiener & inocula & Recovery \\
\hline Initial PNR & 1.00 & & & & & & & \\
\hline Zn tolerance & 0.26 & 1.00 & & & & & & \\
\hline AOB abundance & 0.20 & $0.47^{1}$ & 1.00 & & & & & \\
\hline $\mathrm{AOB}$ richness & 0.18 & $-0.44^{1}$ & 0.11 & 1.00 & & & & \\
\hline \# AOB bands & 0.26 & $-0.45^{1}$ & 0.03 & $0.93^{1}$ & 1.00 & & & \\
\hline AOB Sh-Wi & 0.20 & -0.38 & 0.14 & $0.89^{1}$ & $0.92^{1}$ & 1.00 & & \\
\hline \# inocula & $0.72^{1}$ & 0.00 & -0.07 & $0.55^{1}$ & $0.59^{1}$ & $0.42^{1}$ & 1.00 & \\
\hline Recovery & $0.75^{1}$ & $0.50^{1}$ & 0.20 & -0.10 & -0.05 & -0.08 & $0.46^{1}$ & 1.00 \\
\hline
\end{tabular}

${ }^{1}$ Significant correlations $(\mathrm{p}<0.05)$ 
Table 4: Stepwise multiple linear regression to explain recovery with microbial properties before Zn stress (units in Table 2) for three groups of data: all treatments, mixtures and single soil inocula treatments. Grouping the measurements by similar initial PNR values did not reveal any factor explaining recovery $(p>0.15)$. Average values were used for the initial PNR, AOB abundance, AOB richness (technical replicates, $n=2)$, treatment replicates $(n=2)$ for recovery were included. Zinc tolerance was not determined in duplicate.

\begin{tabular}{|c|c|c|c|c|c|c|c|c|c|}
\hline \multirow[b]{2}{*}{ All } & \multicolumn{4}{|c|}{ partial } & \multirow[b]{2}{*}{ Mixtures } & \multirow[b]{2}{*}{ Intercept } & \multicolumn{3}{|c|}{ partial } \\
\hline & Intercept & Slope & $\mathrm{R}^{2}$ & $\mathrm{p}$ & & & Slope & $\mathrm{R}^{2}$ & $\mathrm{p}$ \\
\hline Step 1 & & & & & Step 1 & & & & \\
\hline PNR & -23.77 & 34.45 & 0.56 & $<0.0001$ & PNR & -68.85 & 44.73 & 0.56 & 0.01 \\
\hline \multicolumn{10}{|l|}{ Step 2} \\
\hline $\mathrm{Zn}$ & & & & & & & & & \\
\hline tolerance & -49.56 & 9.03 & 0.10 & 0.01 & & & & & \\
\hline PNR & & 30.47 & 0.56 & $<0.0001$ & & & & & \\
\hline
\end{tabular}

\begin{tabular}{lccccc}
\hline $\begin{array}{l}\text { Single } \\
\text { Inocula }\end{array}$ & Soil & & \multicolumn{3}{c}{ partial } \\
& & Intercept & Slope & $\mathrm{R}^{2}$ & $\mathrm{p}$ \\
\hline Step 1 & & & & & \\
& PNR & -21.56 & 41.06 & 0.73 & $<0.0001$ \\
\hline
\end{tabular}




\section{Discussion}

The contribution of the different single soil inocula to the AOB community that developed in the treatments inoculated with mixtures was clearly visible (Figures 2 and Supplementary Information Figure 1), but especially for the Teso soil in mixture 2, suggesting that AOB phylotypes of Teso were positively selected. However, the dominance of the AOB community of Teso in this treatment might also be attributed to the relative larger proportion of the soil in the mixtures to equalize the initial AOB abundance inoculation. Marschner and Rumberger [16] showed that the similarity of the reinoculated soil community with the original soil community increased with increasing inoculum proportion. In general, all soils used in the mixtures contributed to the established community two months after inoculation as displayed in Supplementary Information Figure 1. The obtained dissimilarity shows the creation of a new community structure and hence a modified AOB diversity due to mixing soils. Among all 13 treatments the AOB weighted richness varied between 6 and 114 and the number of bands between 15 and 34 showing the creation of treatments with a varying AOB diversity. In conclusion, we created 13 different soil microbial communities with contrasting AOB diversity, without changing abiotic soil properties, such as eCEC and $\mathrm{pH}$ by inoculating a sterilized soil with aliquots of soils and soil mixtures. In addition, potential nitrification was detected in all treatments after two months incubation. This potential nitrification (initial PNR) was different among treatments and was not correlated with the AOB abundance. Apparently, a similar AOB abundance among treatments does not ensure a similar activity, suggesting that not all populations are active or that nitrification activity is different among different phylotypes. 
The applied $\mathrm{Zn}$ stress after two months incubation was sufficient to completely inhibit nitrification after one week $\mathrm{Zn}$ exposure in all $\mathrm{Zn}$ amended soils of all treatments. As such, the AOB diversity did not affect the initial resistance to the applied $\mathrm{Zn}$ stress, which is in contrast to a previous study where a positive relation between diversity and resistance of the plant decomposition rate directly after copper addition was found [7]. This lack of an effect of AOB diversity on the resistance might be ascribed to the larger $\mathrm{Zn}$ dose used in this study (1500 $\mathrm{mg} \mathrm{Zn}$ $\mathrm{kg}^{-1}$ ), which might not be suitable for resistance testing. This dose was chosen based on a previous study in another soil, which showed that adaptation of potential nitrification occurred concomitant with changes of the nitrifying community at this concentration [31]. Lower concentrations might fail to induce changes of the community structure.

Potential nitrification recovered in some of the $\mathrm{Zn}$ amended soils after six months $\mathrm{Zn}$ exposure. It is speculated that a soil with a more diverse microbial community can adapt faster, because of a larger likelihood that populations tolerant to the disturbance or stress are present and that more populations are available to phenotypically or genotypically adapt to the changing environment [15]. However, none of the diversity indices correlated to recovery despite a marked difference in diversity among treatments. The number of different soil inocula - a nominal proxy of the potential initial diversity - was positively correlated to the recovery (Table 3). This weak correlation ( $\mathrm{r}=0.46$, Table 3$)$ is, however, based on only five treatments which had more than one inoculum. The number of inocula might also indirectly enhanced the recovery by increasing the initial PNR, since both are positively correlated ( $\mathrm{r}=0.75$, Table 3$)$. Studies in which the diversity was experimentally decreased by inoculating soil dilutions previously showed similar trends. Griffiths et al. [8] observed no consistent effect of the microbial diversity on recovery of the potential nitrification and thymidine incorporation to $\mathrm{Cu}$, and Wertz et al. [37] similarly observed 
no effect of decreasing nitrite oxidizers diversity on the recovery of the nitrification after a transient heat stress in soil. In general, a lack of correlation between diversity and recovery when the microbial diversity is either experimentally increased or decreased, is observed among different studies and this might be attributed to the inherently large diversity and, hence, the functional redundancy of the soil microbial community compared to other ecosystems. As such, even the diversity and functional redundancy of the nitrifying community, thought to be limited compared to other microbial communities [13], appears to be sufficient to survive stress and restore the community's function after long term exposure to stress. This can also explain the apparent inherent ability of the ammonium oxidizing community to adapt to $\mathrm{Zn}$ in soils as shown in several studies [19-20; 30-31].

Recovery was most strongly explained by the initial PNR (potential nitrification activity). It is not very clear how a potential activity might explain the recovery, the PNR is indeed not the rate of nitrification in soils that are initially contaminated with $\mathrm{Zn}$ but it is the potential rate at unlimited $\mathrm{NH}_{4}{ }^{+}$-supply in absence of $\mathrm{Zn}$. All soils were amended with a large $\mathrm{NH}_{4}{ }^{+}$-dose before the start of incubation. Likely, a high potential activity in a soil (high PNR) reflects the presence of active biomass ready to nitrify and grow when conditions are possible, even at slower rates under toxic conditions such as Zn stress, while a low PNR reflects a very weak potential activity for nitrification or growth in any condition. We previously showed faster adaptation of potential nitrification to $\mathrm{Zn}$ at increasing nitrification activity [31]. In the latter, activity was increased by adding increasing doses of $\mathrm{NH}_{4}{ }^{+}-\mathrm{N}$ to the soil. In this study here, differences in initial potential nitrification activity were not due to differences in initial AOB abundance, since the initial AOB abundance did not significantly differ among treatments. Differences in activity are therefore most likely due to differences in the nitrifying community composition. The contribution of AOA 
to soil nitrification is still debated $[11 ; 39]$ and was not studied in the soils used for inoculation. It is therefore unknown whether the lack of correlation of the AOB abundance to the PNR after 2 months incubation and the lack of correlation of the AOB diversity to the recovery is due to differences of the contribution of AOA to nitrification, or of the AOA community composition, its diversity and abundance among the treatments. However, it is thought that AOA are dominant nitrifiers in acidic soils $(<5.5)$ and that $\mathrm{AOB}$ preferentially use $\mathrm{NH}_{4}{ }^{+}$, while AOA have more affinity for organic $\mathrm{N}$ [26]. The weight of evidence hence suggests that AOB are more important in this study than AOA when assessing potential nitrification. Indeed, the soil used in this study has a $\mathrm{pH}$ well above 5.5 and therefore the relative importance of $\mathrm{AOB}$ in nitrification is larger [26]. More importantly, $\mathrm{NH}_{4}{ }^{+}$is supplied in excess for assessing PNR favouring AOB activity even in acidic soils [32]. In addition, previous studies in two different acidic soils showed that AOA do not play a role in recovery of nitrification to $\mathrm{Zn}$ stress and that the relative abundance of AOA compared to AOB in soil decreased after long term Zn exposure $[19 ; 31 ; 32]$. Nevertheless, study of the contribution of AOA in soil nitrification under different soil conditions deserves dedicated methodologies which discriminate between $\mathrm{AOB}$ and $\mathrm{AOA}$ (e.g. stable isotope probing, RNA abundance analysis).

This study shows that recovery of potential nitrification to $\mathrm{Zn}$ stress is not explained by the AOB diversity. However, potential nitrification activity and initial $\mathrm{Zn}$ tolerance are correlated to recovery which are obviously determined by the nitrifying community composition. This study therefore suggests that the potential community activity and composition explain recovery to stress in soil, rather than diversity as such. 


\section{Acknowledgments}

This work was financially supported by the Institute for the Promotion of Innovation through Science and Technology in Flanders (IWT-Vlaanderen) and by a post-doctoral mandate of the KULeuven (PDM-KULeuven). The authors thank Dr. Jelle Mertens for help with the experimental design.

\section{References}

1. Díaz-Raviña M, Bååth E (1996) Development of metal tolerance in soil bacterial communities exposed to experimentally increased metal levels. Appl Environ Microbiol 62: $2970-2977$

2. Díaz-Raviña M, Bååth E (2001) Response of soil bacterial communities pre-exposed to different metals and reinoculated in an unpolluted soil. Soil Biol Biochem 33: 241-248

3. Doelman P, Haanstra L (1989) Short-Term and Long-Term Effects of Heavy-Metals on Phosphatase-Activity in Soils - an Ecological Dose-Response Model Approach. Biol Fertil Soils 8: 235-241

4. Fait G, Broos K, Zrna S, Lombi E, Hamon R (2006) Tolerance of nitrifying bacteria to copper and nickel. Environ Toxicol Chem 25: 2000-2005

5. Frostegård A, Tunlid A, Bååth E (1996) Changes in microbial community structure during long-term incubation in two soils experimentally contaminated with metals. Soil Biol Biochem 28: 55-63 
6. Girvan MS, Campbell CD, Killham K, Prosser JI, Glover LA (2005) Bacterial diversity promotes community stability and functional resilience after perturbation. Env Microbiol 7: $301-313$

7. Griffiths BS, Ritz K, Bardgett RD, Cook R, Christensen S, Ekelund F, Sorensen SJ, Bååth E, Bloem J, de Ruiter PC, Dolfing J, Nicolardot B (2000) Ecosystem response of pasture soil communities to fumigation-induced microbial diversity reductions: an examination of the biodiversity-ecosystem function relationship. Oikos 90: 279-294

8. Griffiths BS, Ritz K, Wheatley R, Kuan HL, Boag B, Christensen S, Ekelund F, Sorensen SJ, Muller S, Bloem J (2001) An examination of the biodiversity-ecosystem function relationship in arable soil microbial communities. Soil Biol Biochem 33: 1713-1722

9. Griffiths BS, Bonkowski M, Roy J, Ritz K (2001) Functional stability, substrate utilisation and biological indicators of soils following environmental impacts. Applied Soil Ecology 16: 49-61

10. Griffiths BS, Hallett PD, Kuan HL, Gregory AS, Watts CW, Whitmore AP (2008) Functional resilience of soil microbial communities depends on both soil structure and microbial community composition. Biol Fertil Soils 44: 745-754

11. Jia ZJ, Conrad R (2009) Bacteria rather than Archaea dominate microbial ammonia oxidation in an agricultural soil. Env Microbiol 11: 1658-1671

12. Konopka A (2009) What is microbial community ecology? ISME 3: 1223-1230

13. Kowalchuk GA, Stephen JR (2001) Ammonia-oxidizing bacteria: A model for molecular microbial ecology. Annual Review of Microbiology 55: 485-529 
14. Leininger S, Urich T, Schloter M, Schwark L, Qi J, Nicol GW, Prosser JI, Schuster SC, Schleper C (2006) Archaea predominate among ammonia-oxidizing prokaryotes in soils. Nature 442: 806-809

15. Loreau M, Naeem S, Inchausti P, Bengtsson J, Grime JP, Hector A, Hooper DU, Huston MA, Raffaelli D, Schmid B, Tilman D, Wardle DA (2001) Ecology - Biodiversity and ecosystem functioning: Current knowledge and future challenges. Science 294: 804-808

16. Marschner P, Rumberger A (2004) Rapid changes in the rhizosphere bacterial community structure during re-colonization of sterilized soil. Biol Fertil Soils 40: 1-6

17. Marzorati M, Wittebolle L, Boon N, Daffonchio D, Verstraete W (2008) How to get more out of molecular fingerprints: practical tools for microbial ecology. Env Microbiol 10: $1571-1581$

18. Mertens B, Boon N, Verstraete W (2005) Stereospecific effect of hexachlorocyclohexane on activity and structure of soil methanotrophic communities. Env Microbiol 7: 660-669

19. Mertens J, Broos K, Wakelin SA, Kowalchuk GA, Springael D, Smolders E (2009) Bacteria, not archaea, restore nitrification in a zinc-contaminated soil. ISME 3: 916-923

20. Mertens J, Springael D, De Troyer I, Cheyns K, Wattiau P, Smolders E (2006) Long-term exposure to elevated zinc concentrations induced structural changes and zinc tolerance of the nitrifying community in soil. Env Microbiol 8: 2170-2178

21. Naeem S, Li SB (1997) Biodiversity enhances ecosystem reliability. Nature 390: 507-509

22. Nicol GW, Schleper C (2006) Ammonia-oxidising Crenarchaeota: important players in the nitrogen cycle? Trends Microbiol 14: 207-212 
23. Norton JM, Alzerreca JJ, Suwa Y, Klotz MG (2002) Diversity of ammonia monooxygenase operon in autotrophic ammonia-oxidizing bacteria. Arch Microbiol 177: $139-149$

24. Okano Y, Hristova KR, Leutenegger CM, Jackson LE, Denison RF, Gebreyesus B, Lebauer D, Scow KM (2004) Application of real-time PCR to study effects of ammonium on population size of ammonia-oxidizing bacteria in soil. Appl Environ Microbiol 70: $1008-1016$

25. Oorts K, Bronckaers H, Smolders E (2006) Discrepancy of the microbial response to elevated copper between freshly spiked and long-term contaminated soils. Environ Toxicol Chem 25: 845-853

26. Prosser JI, Nicol GW (2012) Archaeal and bacterial ammonia-oxidisers in soil: the quest for niche specialisation and differentiation. Trends Microbiol 20: 523-531

27. Purkhold U, Pommerening-Roser A, Juretschko S, Schmid MC, Koops HP, Wagner M (2000) Phylogeny of all recognized species of ammonia oxidizers based on comparative 16S rRNA and amoA sequence analysis: Implications for molecular diversity surveys. Appl Environ Microbiol 66: 5368-5382

28. Ramette A (2007) Multivariate analyses in microbial ecology. Fems Microbiology Ecology 62: 142-160

29. Rotthauwe JH, Witzel KP, Liesack W (1997) The ammonia monooxygenase structural gene amoA as a functional marker: Molecular fine-scale analysis of natural ammoniaoxidizing populations. Appl Environ Microbiol 63: 4704-4712

30. Rusk JA, Hamon RE, Stevens DP, McLaughlin MJ (2004) Adaptation of soil biological nitrification to heavy metals. Environ Sci Technol 38: 3092-3097 
31. Ruyters S, Mertens J, Springael D, Smolders E (2010) Stimulated activity of the soil nitrifying community accelerates community adaptation to $\mathrm{Zn}$ stress. Soil Biol Biochem 42: $766-772$

32. Ruyters S, Nicol GW, Prosser JI, Lievens B, Smolders E (2013) Activity of the ammonia oxidising bacteria is responsible for zinc tolerance development of the ammonia oxidising community in soil: A stable isotope probing study. Soil Biol Biochem 58: 244-247

33. Smolders E, Brans K, Coppens F, Merckx R (2001) Potential nitrification rate as a tool for screening toxicity in metal-contaminated soils. Environ Toxicol Chem 20: 2469-2474

34. Smolders E, Oorts K, van Sprang P, Schoeters I, Janssen CR, McGrath SP, McLaughlin MJ (2009) Toxicity of Trace Metals in Soil as Affected by Soil Type and Aging after Contamination: Using Calibrated Bioavailability Models to Set Ecological Soil Standards. Environ Toxicol Chem 28: 1633-1642

35. Stephen JR, Kowalchuk GA, Bruns MAV, McCaig AE, Phillips CJ, Embley TM, Prosser JI (1998) Analysis of beta-subgroup proteobacterial ammonia oxidizer populations in soil by denaturing gradient gel electrophoresis analysis and hierarchical phylogenetic probing. Appl Environ Microbiol 64: 2958-2965

36. Trevors JT (1996) Sterilization and inhibition of microbial activity in soil. J Microbiol Methods 26: 53-59

37. Wertz S, Degrange V, Prosser JI, Poly F, Commeaux C, Guillaumaud N, Le Roux X (2007) Decline of soil microbial diversity does not influence the resistance and resilience of key soil microbial functional groups following a model disturbance. Env Microbiol 9: 2211-2219 
38. Witter E, Gong P, Bååth E, Marstorp H (2000) A study of the structure and metal tolerance of the soil microbial community six years after cessation of sewage sludge applications. Environ Toxicol Chem 19: 1983-1991

39. Zhang LM, Offre PR, He JZ, Verhamme DT, Nicol GW, Prosser JI (2010) Autotrophic ammonia oxidation by soil thaumarchaea. Proc Natl Acad Sci U S A 107: 17240-17245 
Mixture 1

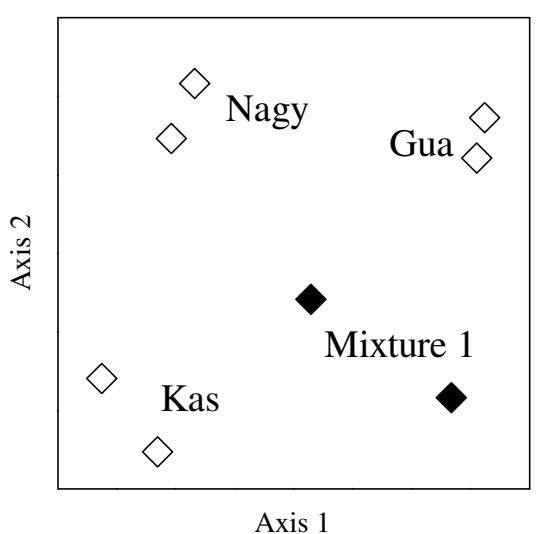

Mixture 4

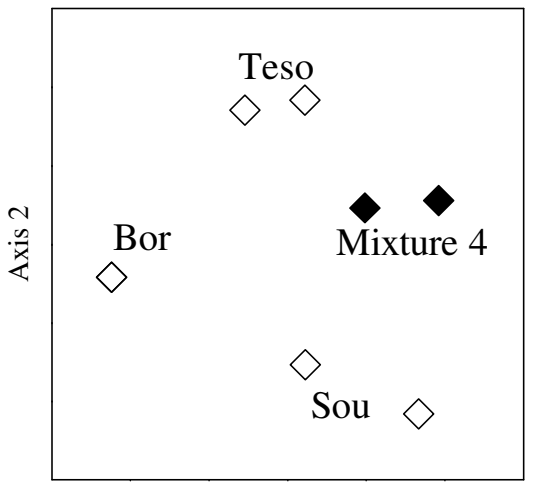

Axis 1
Mixture 2

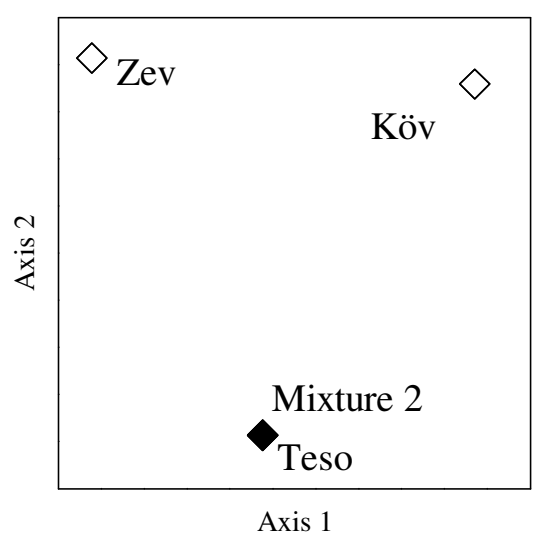

Mixture 5

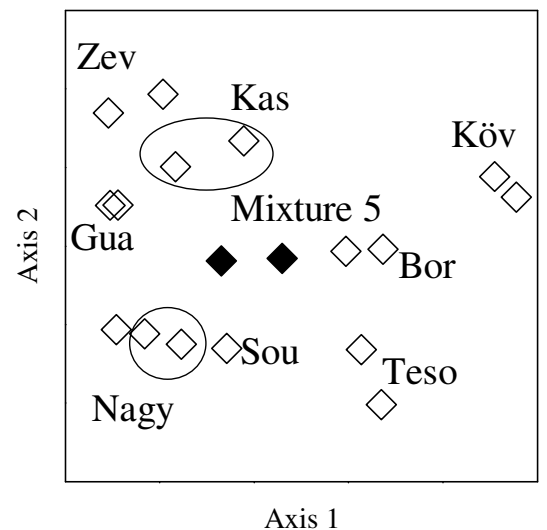

Mixture 3

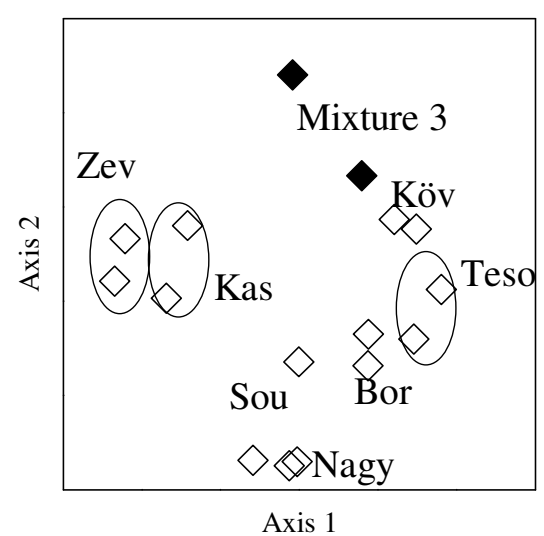

Köv: Kövlinge

Nagy: Nagyhörcsök

Kas: Kasterlee

Bor: Borris

Sou: Souli

Zev: Zeveren

Gua: Guadalajara

Teso: Teso

Supplementary Information Figure 1: Two-dimensional presentation of the AOB amoA DGGE profiles of the treatments inoculated with the mixtures in relation to the single soil inocula treatments used in the mixture based on nMDS ordination (Bray-Curtis similarity) as measured after 2 months incubation prior to $\mathrm{Zn}$ amendment. Mixture 2 showed great resemblance with Teso. In the other mixtures the inoculated soils all contributed to the new established community after two months of incubation. Treatments inoculated with mixtures: filled symbols; single soil inocula treatments: open symbols. 
Supplementary Table 1: Overview of the diversity measures (expected and measured based on AOB amoA DGGE profiling) of the inoculated treatments before $\mathrm{Zn}$ stress (two months after inoculation).

\begin{tabular}{|c|c|c|c|c|c|c|c|c|c|}
\hline \multirow{3}{*}{$\begin{array}{l}\text { Treatment } \\
\text { (inocula) } \\
\text { Mixture } 1\end{array}$} & \multicolumn{3}{|c|}{ Expected $^{1}$ AOB Diversity } & \multicolumn{6}{|c|}{ Measured AOB Diversity } \\
\hline & \multirow{2}{*}{$\begin{array}{c}\text { Richness } \\
83\end{array}$} & \multirow{2}{*}{$\begin{array}{c}\text { \# bands } \\
43\end{array}$} & \multirow{2}{*}{$\begin{array}{c}\text { \# inocula } \\
3\end{array}$} & \multicolumn{2}{|c|}{ Richness } & \multicolumn{2}{|c|}{ \# bands } & \multicolumn{2}{|c|}{ Shannon-Wiener } \\
\hline & & & & 33 & $(4.5)$ & 24 & (1) & 3.07 & $(0.29)$ \\
\hline Mixture 2 & 72 & 47 & 3 & 94 & (16.5) & 29 & (2) & 3.28 & $(0.09)$ \\
\hline Mixture 3 & 196 & 105 & 7 & 71 & nd & 25 & nd & 2.88 & nd \\
\hline Mixture 4 & 97 & 50 & 3 & 98 & $(3.5)$ & 27 & (5) & 3.44 & $(0.002)$ \\
\hline Mixture 5 & $>>$ & $>>$ & 22 & 114 & $(51.3)$ & 34 & (1) & 3.40 & $(0.44)$ \\
\hline Kövlinge & 5 & 11 & 1 & 6 & $(0.6)$ & 15 & (1) & 2.48 & $(0.05)$ \\
\hline Nagyhörcsök & 17 & 11 & 1 & 7 & $(0.6)$ & 16 & (1) & 2.71 & $(0.05)$ \\
\hline Kasterlee & 46 & 18 & 1 & 10 & $(0.1)$ & 15 & & 2.66 & $(0.02)$ \\
\hline Borris & 46 & 18 & 1 & 20 & $(0.1)$ & 21 & & 2.96 & $(0.005)$ \\
\hline Souli & 15 & 11 & 1 & 57 & $(9.7)$ & 23 & (2) & 3.03 & (0.09) \\
\hline Zeveren & 31 & 15 & 1 & 67 & $(1.8)$ & 24 & & 3.07 & $(0.01)$ \\
\hline Guadalajara & 20 & 14 & 1 & 70 & $(8.2)$ & 24 & (1) & 3.05 & $(0.10)$ \\
\hline Teso & 36 & 21 & 1 & 81 & (19.3) & 31 & (3) & 3.30 & $(0.12)$ \\
\hline
\end{tabular}

${ }^{1}$ The expected AOB diversity is derived from the AOB amoA DGGE profiles of the soils before inoculation (see text); >> Richness of mixture 5 could not be estimated, but is assumed to be very high, since it is comprised of 22 soils. The measured AOB diversity is quantified based on AOB amoA DGGE profiles two months after inoculation and is an average value of two DNA extracts (standard deviation in brackets) except for mixture 3 (one replicate). 